\title{
Farm exposure in utero may protect against asthma, hay fever and eczema
}

\author{
J. Douwes*, S. Cheng*, N. Travier*, C. Cohet*, A. Niesink*, J. McKenzie ${ }^{\#}$, \\ C. Cunningham ${ }^{\star}$, G. Le Gros ${ }^{+}$, E. von Mutius ${ }^{\S}$ and N. Pearce*
}

ABSTRACT: The aim of the present study was to assess which factors contribute to the lower prevalence of allergic diseases in farmers' children, and the importance of timing of exposure.

In a cross-sectional questionnaire survey, asthma symptoms, hay fever and eczema were assessed, as well as current, early and prenatal farm-related exposures in 1,333 farmers' children and 566 reference children aged 5-17 yrs.

Farmers' children had a lower incidence of asthma symptoms and eczema. Current and maternal exposure during pregnancy to animals and/or grain and hay reduced the risk of asthma symptoms, hay fever and eczema. The exposure-response association for maternal exposure was nonlinear for most outcomes. After mutual adjustment, the effects of prenatal exposure remained unchanged whereas current exposure remained protective only for asthma medication, asthma ever and hay fever. Exposure during the first 2 yrs was not associated with symptoms, after controlling for prenatal exposure. A combination of prenatal and current exposure was most strongly associated with wheeze (odds ratio (OR) $0.48,95 \%$ confidence interval $(\mathrm{CI}) \mathbf{0 . 2 8}-0.80$ ), asthma medication (OR $0.50,95 \% \mathrm{Cl} 0.30-0.82$ ), asthma ever (OR $0.50,95 \% \mathrm{Cl} 0.33-0.76$ ), hay fever (OR 0.47, 95\% $\mathrm{Cl} 0.30-0.73$ ) and eczema (OR 0.46, 95\% $\mathrm{Cl} 0.30-0.70$ ).

Prenatal exposure may contribute to the low prevalence of asthma, hay fever and eczema in farmers' children, but continued exposure may be required to maintain optimal protection.

KEYWORDS: Asthma, farming, hygiene hypothesis, prenatal, timing

A $\mathrm{n}$ increasing number of studies have reported a reduced risk of atopy, hay fever, asthma and eczema in farmer's children and adolescents [1, 2]. Recent studies among adult farmers have demonstrated that protection against atopy and atopic asthma may continue into adulthood [3-5], and that long-term continual exposure may be required to maintain optimal protection [6-8]. The specific protective factors were not conclusively determined, although it was indicated that contact with livestock as well as consumption of unpasteurised milk were particularly protective $[2,9]$.

The underlying immunological mechanisms involved in protective effects are still unclear, but innate immune responses are believed to play a key role. In particular, it has been hypothesised that bacterial endotoxin and/or other microbial exposures associated with animal contact and/or consumption of unpasteurised milk may activate innate immune pathways through expression of Toll-like receptors (TLRs) and CD14 [10]. These exposures may thereby suppress T-helper cell (Th) type 2 expansion and the development of immunoglobulin (Ig)E antibodies and Th2-dependent diseases, including allergic asthma, hay fever and eczema [11]. Although it has been suggested that these protective effects primarily arise from exposures during the first years of life [12], little is known as to whether this period is critical, and/or whether later and prenatal exposures may also play a role. A recent study in Europe reported that maternal exposure to the farm environment during pregnancy was more strongly associated with atopic sensitisation and innate immunity than current exposures [10]. These results suggest that farming-related exposures during pregnancy may modulate immune responses and possibly reduce disease occurrence in the offspring. Other studies have shown protective effects on atopy and asthma of dietary factors during pregnancy such as fish, apple and vitamin D [13-15]. The opposite has been suggested for maternal smoking and prenatal exposures to insecticides [16-18].

In the present cross-sectional study, the effects of current, early and prenatal farming exposures were assessed in children from dairy, sheep and beef, and horticulture farms, and a rural, nonfarming control population.

\section{AFFILIATIONS}

${ }^{\star}$ Centre for Public Health Research,

"Research Centre for Māori Health and Development, Research School of Public Health, Massey University, ${ }^{+}$Malaghan Institute for Medical Research, Victoria University, Wellington, and

\#Epicentre, Institute of Veterinary, Animal and Biomedical Sciences, Massey University, Palmerston North, New Zealand.

${ }^{\S}$ Dr von Hauner Children's Hospital, University of Munich, Munich, Germany.

CORRESPONDENCE

J. Douwes

Private Box 756

Wellington

New Zealand

Fax: 6443800600

E-mail: j.douwes@massey.ac.nz

Received:

March 212007

Accepted after revision:

April 152008

\section{SUPPORT STATEMENT}

The Centre for Public Health Research is supported by a Programme Grant that includes funding for the current study and J. Douwes is supported by a Sir Charles Hercus Research Fellowship, both from the Health Research Council of New Zealand.

\section{STATEMENT OF INTEREST} None declared. 


\section{MATERIALS AND METHODS}

\section{Study design and population}

The methods for the present study were based on those of the European study on atopy and asthma in farmers' children, known as the Prevention of Allergy - Risk factors for Sensitisation in children related to Farming and Anthroposophic Lifestyle (PARSIFAL) study [19]. The current study involved a survey of 2,509 farming families and 1,001 nonfarming families of working age. The findings in children are presented.

Farming families living in the lower half of the North Island were randomly selected from a national database of farms in New Zealand. The current authors aimed for equal numbers of dairy, sheep and beef, and horticulture farming families. However, there were relatively fewer horticultural farms (crop farms and orchards), resulting in lower numbers for this group. A rural control group of nonfarmers from the same region (adults aged 25-49 yrs) were randomly chosen from the New Zealand Electoral Roll, and those with children were included in the analyses.

Subjects were asked to complete a postal survey for themselves and their children aged 5-17 yrs (if any). A maximum of two children were included per household; if the family had more than two children within the specified age range, the two oldest children were selected, because wheeze in younger children is less clearly associated with asthma [20]. Those who had not responded to the postal survey after three reminders were asked to complete the questionnaire(s) by telephone. An overview of the recruitment, exclusions and refusals is presented in figure 1. All subjects gave written informed consent, and the study was approved by the Massey University Human Ethics Committee (Palmerston North, New Zealand; WGTN protocol 02/105).

\section{Questionnaire}

The symptom prevalence was assessed using a standardised questionnaire based on the International Study of Asthma and Allergies in Childhood (ISAAC) postal questionnaire [21]. The current authors focussed on the following questions: "Has your child had wheezing or whistling in the chest in the past 12 months?"; " Has your child ever had asthma?"; "In the past 12 months, has your child taken any medicines, pills or other medication for asthma?"; "Has your child ever had hay fever?"; and "Has your child ever had eczema?".

In the same questionnaire, "environmental" exposures were assessed, such as diet and contact with animals and/or hay and grain products. The questions used to assess farm exposures are summarised in table 1 and focus on exposures during three time periods in the child's life: current, lifetime and prenatal. "Current exposures" relate to exposures in the previous 12 months; "lifetime exposures" relate to exposures at any stage in life; and "prenatal exposures" relate to exposures of the mother during pregnancy. For current and prenatal exposures, the frequency of the exposures was also assessed, and for lifetime exposures a distinction was made between exposures before and after 2 yrs of age (table 1). Information was not collected on lifetime exposure to grain and hay products and consumption of unboiled milk.

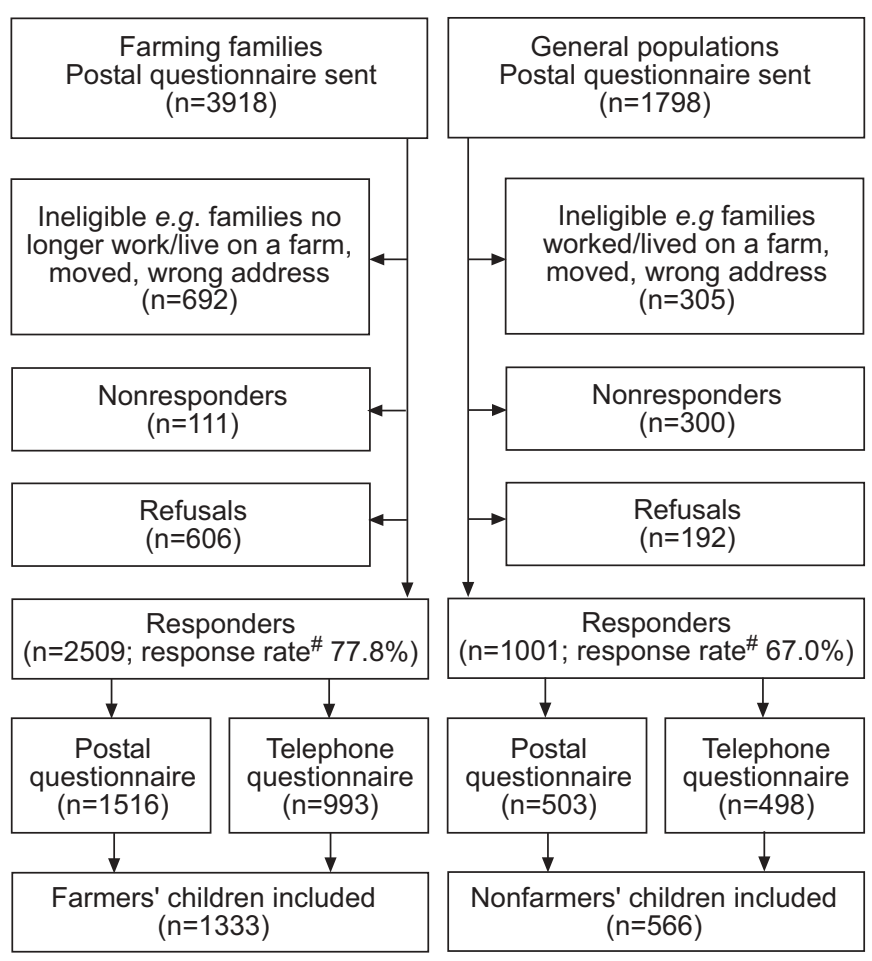

FIGURE 1. Flow diagram describing subject recruitment, exclusion and refusals \#: the number of responders divided by the total number of eligible families.

\section{Statistical analyses}

Chi-squared tests and unpaired t-tests were performed to test differences in prevalence and mean levels, respectively. Crude and adjusted prevalence odds ratios (ORs) were calculated using logistic regression analyses. Since children from the same household were included (with a maximum of two per household), the data were not completely independent. Therefore, clustered robust standard errors [22] were applied, using the family unit as the cluster variable.

Multiple logistic regression models were constructed by adding one exposure variable at a time, commencing with the main exposure variables (i.e. those relating to farming exposure) followed by the potential confounders that showed the strongest effects in univariate analyses. At each step, ORs were checked for signs of confounding, and standard errors were checked for signs of multicollinearity. Due to multicollinearity between animal exposures and grain/hay exposures, the effect of each of these exposures could not be assessed independently (i.e. these could not be included in the same multiple regression model). Since most evidence points toward the potential protective effects of animal contact, exposure to animals was selected as the main exposure variable in the final multivariate model. The final model consisted of variables representing animal exposures at different time-points (i.e. exposures in the past 12 months, exposures in the first 2 yrs of life and after the first 2 yrs, and exposures of the mother during pregnancy), as well as several potential confounders (age, sex, ethnicity, mother's education level, smoking in the house, farm type, and parental asthma, hay fever and eczema). Apart from exposures to grain/hay, no other problems of multicollinearity were observed for 


\section{TABLE 1 Questions used to assess current, lifetime and prenatal farm exposures}

\begin{tabular}{|c|c|c|c|}
\hline Type of exposure & Timing of exposure & Question & Answers \\
\hline \multirow[t]{3}{*}{ Farm animals $^{\#}$} & Current & $\begin{array}{l}\text { In the last } 12 \text { months, how often on average did your child } \\
\text { have contact with farm animals? }\end{array}$ & $\begin{array}{l}\text { Never; less than once a week; at least } \\
\text { once a week; at least once a day }\end{array}$ \\
\hline & Lifetime exposure & $\begin{array}{l}\text { Does or did your child have at least once a week contact with } \\
\text { any of the following animals (cattle, sheep, horses, pigs, } \\
\text { poultry, goats or working dogs) at any stage in their life? }\end{array}$ & Yes; no \\
\hline & Prenatal exposure & $\begin{array}{l}\text { How often did the mother have contact with farm animals } \\
\text { during the pregnancy? }\end{array}$ & $\begin{array}{l}\text { Never; less than once a week; At least } \\
\text { once a week; At least once a day }\end{array}$ \\
\hline Grain or hay & Current & $\begin{array}{c}\text { In the last } 12 \text { months, how often on average did your child } \\
\text { go into a building containing agricultural products, like } \\
\text { grain or hay? }\end{array}$ & $\begin{array}{l}\text { Never; less than once a week; at least } \\
\text { once a week; at least once a day }\end{array}$ \\
\hline
\end{tabular}

any of the other exposure variables and/or confounders. In particular, agreement between variables representing animal exposures at different time-points was relatively low. For example the kappa statistic for animal contact in the last 12 months and animal contact of the mother during pregnancy was only 0.24 (95\% confidence interval (CI) $0.22-0.26)$. In addition to these potential confounders, the following variables were also tested: number of siblings, previous and current paracetamol use, antibiotic use, current and previous cat and/or dog ownership, vaccinations, body mass index, and dietary factors. However, these did not affect the associations between farming exposure and symptoms and were, therefore, not included in the final model.

The independent and joint effects of current and prenatal exposure were also assessed. For that purpose, prenatal and current exposure were dichotomised, with "frequent exposure" being defined as contact with animals at least once a day (compared with contact less than once a day). Subsequently, comparisons were made between those who were frequently exposed in both periods, those who were only currently exposed, and those who were exposed in utero but not currently; the reference group consisted of children who had no exposure in either period.

\section{RESULTS}

The 2,509 farming families and 1,001 reference families that participated (response rates of 77.8 and $67.0 \%$, respectively) included 1,333 farmers' children and 566 reference children (fig. 1). Compared with the farmers' children, the reference group had a higher proportion of Māori and Pacific children. They also had more smokers in the house and more siblings or parents with asthma, hay fever and eczema. Children of dairy farmers had more siblings than the children in the reference group (table 2).
Symptoms were less prevalent in farmers' children: the ORs were statistically significant for wheeze in the last 12 months, asthma ever and eczema ever. These effects were most pronounced for livestock farmers (table 3). Univariate regression analyses to assess specific farming-related exposures that could explain these differences showed that contact with farm animals in the first 2 yrs of life was inversely associated with all symptoms $(\mathrm{p}<0.05)$. A dose-response association was also demonstrated with animal contact in the past 12 months (table 4). Similar dose-dependent associations were found for having been in a building containing farm products such as hay and grain. Children whose mothers had frequent exposure to farm animals during pregnancy were also less likely to have symptoms, with a dose-response trend for hay fever and eczema. Current wheeze, asthma ever and asthma medication were also less prevalent compared with the never-exposed group, but these effects were only observed for children whose mothers had been exposed infrequently (less than once a week) and frequently (at least once a day). No effect was seen for the children whose mothers had been exposed at an intermediate frequency (at least once a week but less than once a day). A similar nonlinear pattern was seen for having been in a building with farm products such as grain and hay. There were no apparent differences in risk according to the types of animals to which pregnant mothers and children were exposed (cattle, sheep, pigs, etc.; data not shown). Consumption of raw milk fresh from the farm was also inversely associated with asthma symptoms, hay fever and eczema (table 4).

Subsequently, multiple regression analyses were conducted (table 5) in order to establish which of the farming-related exposures were independent predictors of the lower prevalence of asthma symptoms, hay fever and eczema. However, since animal and grain/hay exposures were highly correlated, it was not possible to test both exposures independently; 


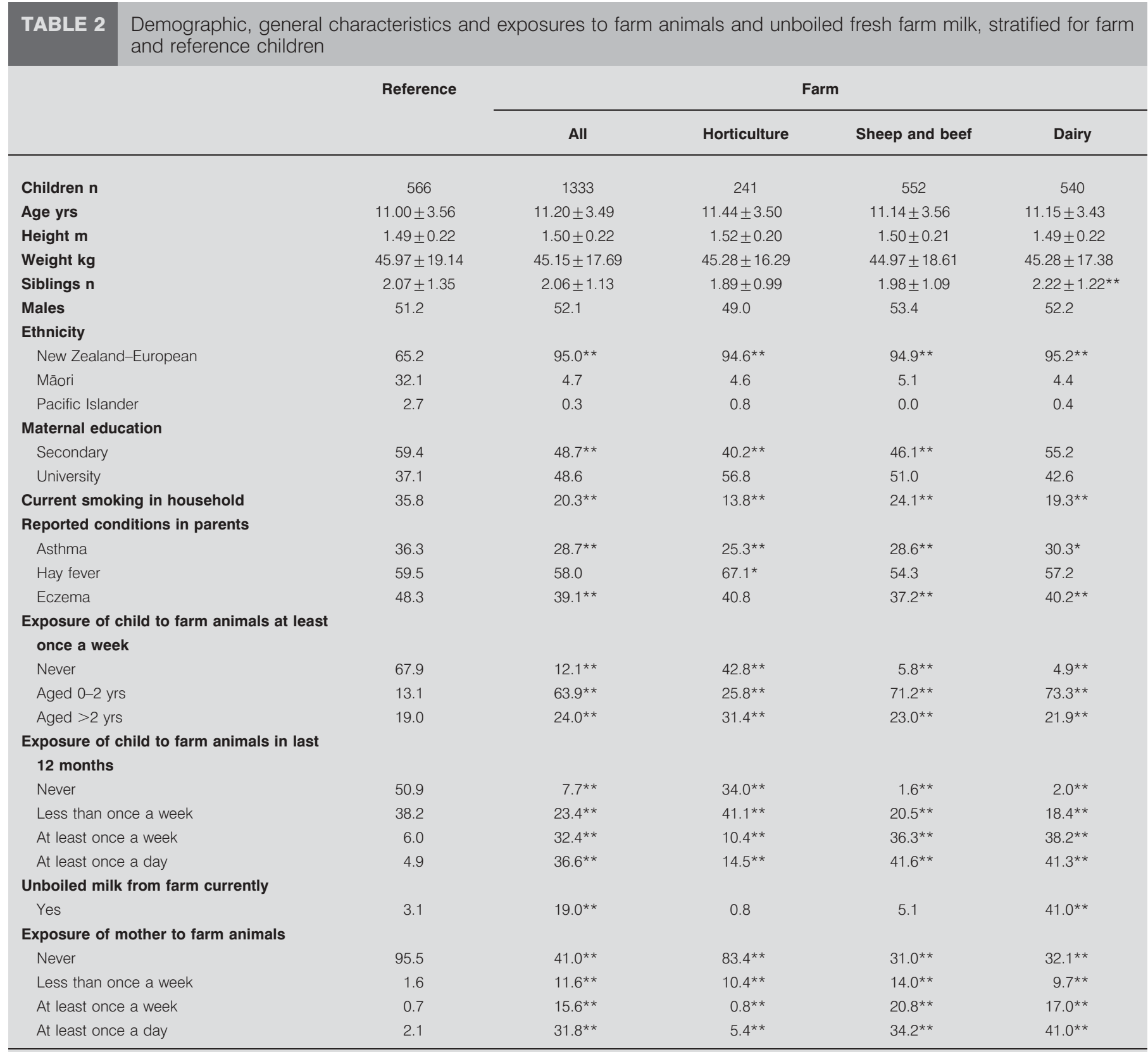

Data are presented as mean \pm SD or $\%$, unless otherwise stated. ${ }^{*}: p<0.05$; and ${ }^{*}: \mathrm{p}<0.01$, compared with the reference group.

therefore, the current authors chose to include only animal contact. The protective effect of maternal exposures during pregnancy remained almost unchanged after adjustment for potential confounders for all study outcomes. Current exposure of the child to farm animals remained protective for asthma medication, asthma ever and hay fever, whereas significant associations were no longer found for wheeze and eczema. In addition, contact with farm animals during the first 2 yrs of life was no longer associated with symptoms. Raw milk was also no longer significantly associated with symptoms. Further adjustments for number of siblings, previous and current paracetamol use, antibiotics, current and previous cat and/or dog ownership, vaccinations, body mass index and dietary factors did not significantly alter the results (data not shown).

For all symptoms, the strongest reduced risks were in those children with both prenatal and current exposure to farm animals (wheeze: OR 0.48, 95\% CI 0.28-0.80; asthma medication: OR 0.50, 95\% CI 0.30-0.82; asthma ever: OR 0.50, 95\% CI 0.33-0.76; hay fever ever: OR 0.47, 95\% CI 0.30-0.73; eczema ever: OR $0.46,95 \%$ CI $0.30-0.70$; fig. 2). Children with prenatal exposure only had an intermediate risk (wheeze: OR $0.62,95 \%$ CI 0.39-0.99; asthma medication: OR $0.72,95 \%$ CI $0.45-1.17$; 
TABLE 3 Asthma symptoms, hay fever and eczema in farming and reference children

\begin{tabular}{|c|c|c|c|c|c|c|c|c|c|}
\hline & \multirow{3}{*}{$\begin{array}{c}\text { Reference } \\
\text { prevalence } \\
\%\end{array}$} & \multicolumn{8}{|c|}{ Farm } \\
\hline & & \multicolumn{2}{|r|}{ All } & \multicolumn{2}{|c|}{ Horticulture } & \multicolumn{2}{|c|}{ Sheep and beef } & \multicolumn{2}{|c|}{ Dairy } \\
\hline & & Prevalence \% & OR $(95 \% \mathrm{Cl})$ & Prevalence \% & OR (95\% Cl) & Prevalence \% & OR $(95 \% \mathrm{Cl})$ & Prevalence \% & $\%$ OR $(95 \%$ Cl) \\
\hline Subjects $\mathbf{n}$ & 566 & & 1333 & & 241 & & 552 & & 540 \\
\hline Wheeze ${ }^{\#}$ & 25.1 & 19.5 & $0.72(0.56-0.93)^{\star \star}$ & 22.4 & 0.86 & 20.7 & $0.78(0.58-1.05)$ & 17.0 & $0.61(0.45-0.83)$ \\
\hline $\begin{array}{l}\text { Asthma } \\
\text { medication }\end{array}$ & 22.5 & 19.1 & $0.81(0.63-1.05)$ & 20.7 & $0.90(0.61-1.35)$ & 19.5 & $0.84(0.62-1.14)$ & 17.8 & $0.75(0.54-1.03)$ \\
\hline Asthma ever & 34.2 & 28.5 & $0.77(0.61-0.96)^{*}$ & 34.9 & $1.03(0.75-1.42)$ & 26.5 & $0.69(0.53-0.91)^{\star *}$ & 27.6 & $0.74(0.56-0.97)^{\star}$ \\
\hline Hay fever ever & 27.7 & 26.1 & $0.92(0.73-1.17)$ & 33.8 & $1.33(0.94-1.89)$ & 26.0 & $0.92(0.69-1.22)$ & 22.8 & $0.77(0.58-1.03)$ \\
\hline Eczema ever & 37.3 & 30.2 & $0.73(0.58-0.91)^{\star *}$ & 35.3 & $0.92(0.66-1.28)$ & 29.2 & $0.69(0.53-0.91)^{* *}$ & 29.1 & $0.69(0.53-0.90)^{\star *}$ \\
\hline
\end{tabular}

asthma ever: OR $0.65,95 \%$ CI 0.43-099; hay fever ever: OR 0.55, 95\% CI 0.36-0.85; eczema ever: OR 0.82 , 95\% CI 0.53-1.26), whereas those with only current exposure had no or only a slightly reduced risk (wheeze: $0.90(0.60-1.34)$; asthma medication: OR $0.77,95 \%$ CI 0.52-1.14; asthma ever: OR 0.97, 95\% CI 0.67-1.40; hay fever ever: OR 0.80, 95\% CI 0.56-1.14; eczema ever: OR $0.92,95 \%$ CI $0.65-1.32$ ). The joint effect of prenatal and current farming exposure more than explained the protective effect of farming (table 3). In fact, after adjustment for prenatal and current exposure, the effect of farming disappeared with most ORs close to or just above unity (data not shown).

\section{DISCUSSION}

In the present cross-sectional study, symptoms of asthma and eczema were found to be less prevalent in farmers' children than in rural reference children. Perhaps more interestingly, dose-response associations were demonstrated for maternal exposure to farm animals and/or grain and hay products during pregnancy, and hay fever and eczema in their children. A reduced risk for asthma symptoms and asthma medication use was also shown but no clear dose-response association was found. The strongest protective effects were demonstrated for those children whose mothers had frequent exposures to farm animals during pregnancy and who were also currently exposed.

Several other studies have demonstrated that farmers' children have less asthma, hay fever and eczema [1, 2, 9, 11, 19]. It has also been shown recently that prenatal farm exposures are associated with an increased expression of receptors of innate immunity (TLR2, TLR4 and CD14) and a decrease in atopic sensitisation in children [10]. Asthma, wheeze and hay fever symptoms were also reduced, but these associations were weak and not statistically significant [10]. Therefore, the present study is the first to demonstrate a direct link between exposures in utero and a strong and significant reduction in asthma symptoms, hay fever and eczema. These observations were consistent for all study outcomes after adjusting for several known risk/protective factors, including parental asthma, hay fever and eczema. Due to the cross-sectional design of the study the possibility of recall bias cannot be excluded. However, this is unlikely to explain the findings, since it would require the parents to have knowledge of the potential protective effects of prenatal farm exposures. Nonresponse bias was tested for by comparing the symptom prevalence obtained in the initial postal survey and in the follow-up telephone survey (in those who did not respond to the postal survey), and no differences in prevalence were found between the two surveys for the farming population (data not shown). In the reference population, the prevalence was somewhat higher for those who completed the survey by phone. However, this is unlikely to explain the protective effects observed, since it implies that the slightly higher nonresponse in the reference population would have led to an underestimation of the symptom prevalence in that population and consequently in a reduction of the observed protective effect. In any case, the response was reasonable ( $78 \%$ for farmers and $67 \%$ for the reference population), limiting the potential for significant nonresponse bias.

Since the differences in ethnicity between the reference and the farmers population were substantial (table 2), the analyses were also repeated excluding all Māori and Pacific Island children, but this did not significantly change the results (data not shown). Similarly, restricting the analyses to only the farming population did not change the observed associations between early and current farm-related exposures and asthma symptoms, hay fever and eczema (data not shown). Therefore, the present findings are robust and are unlikely to be explained simply due to general (farm unrelated) differences between farming and nonfarming families.

The most consistent results were found with prenatal exposures but, as demonstrated in multiple regression models (table 5), current exposures were also independently associated with asthma medication, asthma ever and hay fever. Wheeze in the last 12 months also showed a reduced risk, but this did not reach statistical significance. Moreover, the strongest protective effects were found in those children with 


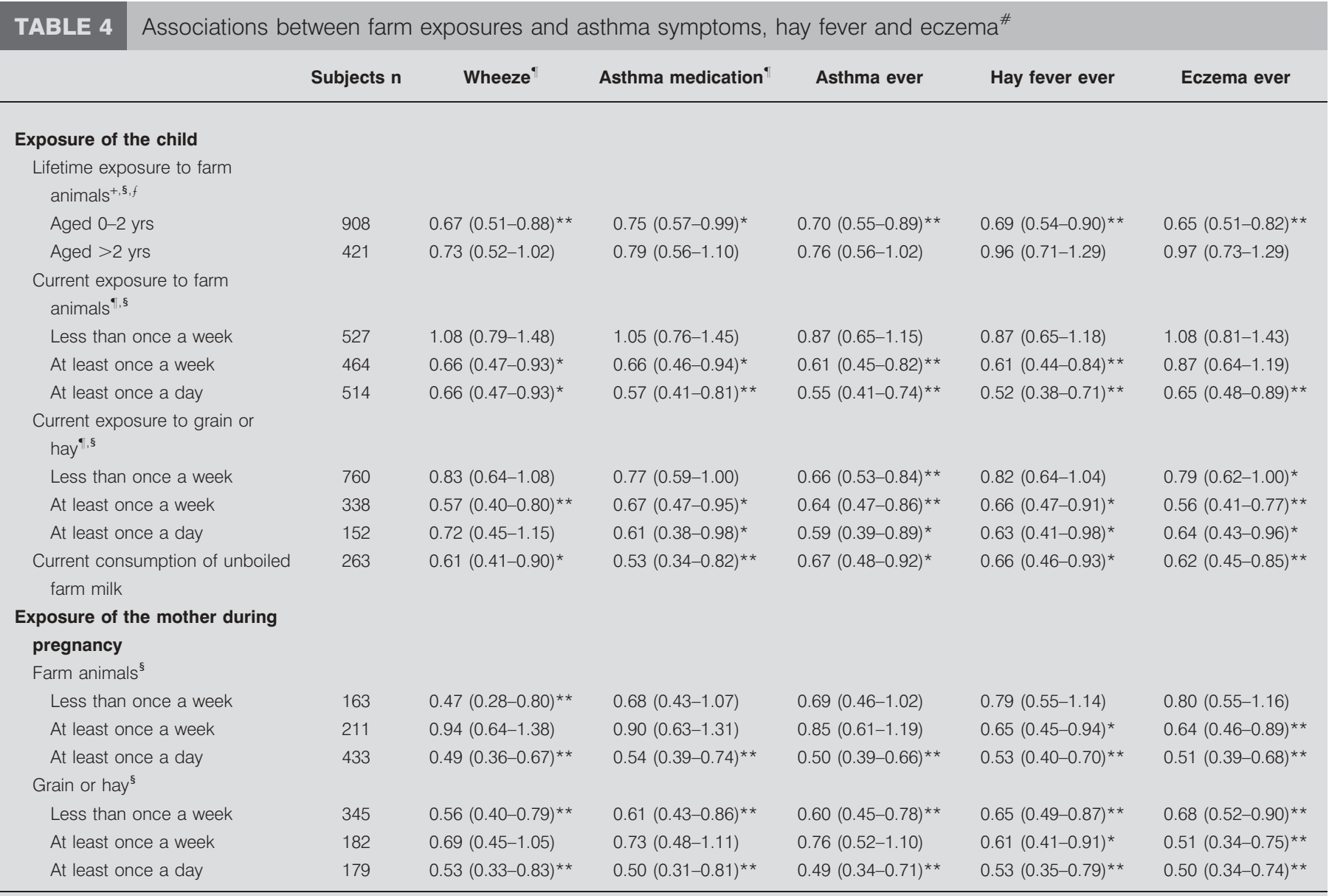

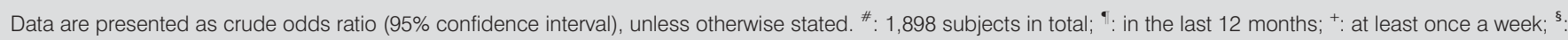
given category versus never; ${ }^{f}$ : reference category was children with no contact with animals. ${ }^{*}: p<0.05 ;{ }^{* *}: p<0.01$.

both prenatal and current exposure (fig. 2). Consistent with this finding, studies in adult farmers have shown that the combination of childhood and current farm exposure was associated with the lowest risk of allergic sensitisation [6], hay fever [7] and asthma [8]. The study by Douwes et al. [8], which was based on the parents of the children in the current study, also showed a dose-dependent inverse association between the combined number of years of farm exposure in childhood and adulthood and asthma symptoms. The combined evidence of these studies suggests that current exposures may play a role in the continued protection against allergic disease later in life. This is plausible, since there is substantial evidence that the immune system is not fixed after the first years of life and immune deviation may take place throughout life [23, 24], although others have argued that immunological reactivity expressed in childhood is already fully established in infancy and early childhood [12]. However, due to its cross-sectional design that was based on questionnaire data only, the present study is not ideally suited to assessing the effects of timing of exposure. Also, because children of different ages (5-17 yrs) were included, "current exposures" do not refer to the same period in life for every child, further complicating the assessment of the importance of timing of exposure.
Interestingly, protective effects were demonstrated not only for asthma and hay fever but also for eczema. The level of agreement between asthma ever and eczema ever $(\kappa 0.24,95 \%$ CI $0.19-0.28$ ) and hay fever ever and eczema ever ( $\kappa 0.17,95 \%$ CI 0.13-0.22) was low, suggesting that the protective effects on eczema are real and were not due to high agreement with the other health outcomes.

Maternal exposure was inversely associated with all symptoms, but a dose-response trend was only found for hay fever and eczema. For asthma symptoms, inverse associations were found for both the "low" and "high" exposure groups, but no association was found for the "intermediate" exposure group. The same pattern was observed when the analyses were adjusted for potential confounders (table 5). The reasons for this are unclear. It is also not clear how maternal exposures during pregnancy affect asthma, hay fever and eczema manifestation in the offspring. One possibility is that maternal immune responses to farm exposures (through cytokine production) may prime the developing foetal immune system [25]. Alternatively, foetal priming to environmental antigens in utero may play a role [26]. Moreover, it has been suggested that environmental exposures may affect gene expression during development in utero, which 
TABLE 5 Association between farming and selected exposures and asthma symptoms, hay fever and eczema ${ }^{\#}$

\begin{tabular}{|c|c|c|c|c|c|c|}
\hline \multicolumn{7}{|l|}{ Exposure of the child } \\
\hline Aged 0-2 yrs & 908 & $0.90(0.58-1.19)$ & $1.27(0.82-1.95)$ & $1.27(0.85-1.89)$ & $1.13(0.75-1.72)$ & $1.03(0.69-1.55)$ \\
\hline Aged $>2$ yrs & 421 & $0.76(0.49-1.19)$ & $1.04(0.67-1.62)$ & $0.98(0.66-1.45)$ & $1.24(0.82-1.88)$ & $1.16(0.79-1.71)$ \\
\hline \multicolumn{7}{|l|}{ Current exposure to farm animals } \\
\hline At least once a day & 478 & $0.80(0.46-1.42)$ & $0.47(0.27-0.82)^{\star \star}$ & $0.60(0.37-0.98)^{*}$ & $0.44(0.26-0.74)^{\star *}$ & $0.82(0.49-1.37)$ \\
\hline $\begin{array}{l}\text { Current consumption of unboiled farm } \\
\text { milk }\end{array}$ & 242 & $0.90(0.55-1.47)$ & $0.66(0.39-1.11)$ & $0.88(0.59-1.31)$ & $0.87(0.57-1.35)$ & $0.91(0.62-1.35)$ \\
\hline \multicolumn{7}{|l|}{$\begin{array}{l}\text { Exposure of the mother during } \\
\text { pregnancy }\end{array}$} \\
\hline
\end{tabular}

Data are presented as odds ratio (95\% confidence interval), unless otherwise stated. ${ }^{\#}$ : adjusted for age, sex, ethnicity, mother's education level, smoking in the house farm type, and parental asthma, hay fever and eczema, as well as all other variables in the model $\left(1,769\right.$ subjects in total); ${ }^{\circ}$ : in the last 12 months; ${ }^{+}$: at least once a week s: given category versus never. *: $p<0.05 ;{ }^{*}: p<0.01$.

could have long-term effects on the immune system in later life [10]. However, the evidence for any of these potential explanations is weak, and further prospective studies are needed to elucidate the underlying immunological mechanisms conclusively.

Animal contact is likely to play a role in the observed protective effects in the current study and those of others $[2,9,10]$. However, in the present study, animal contact was also

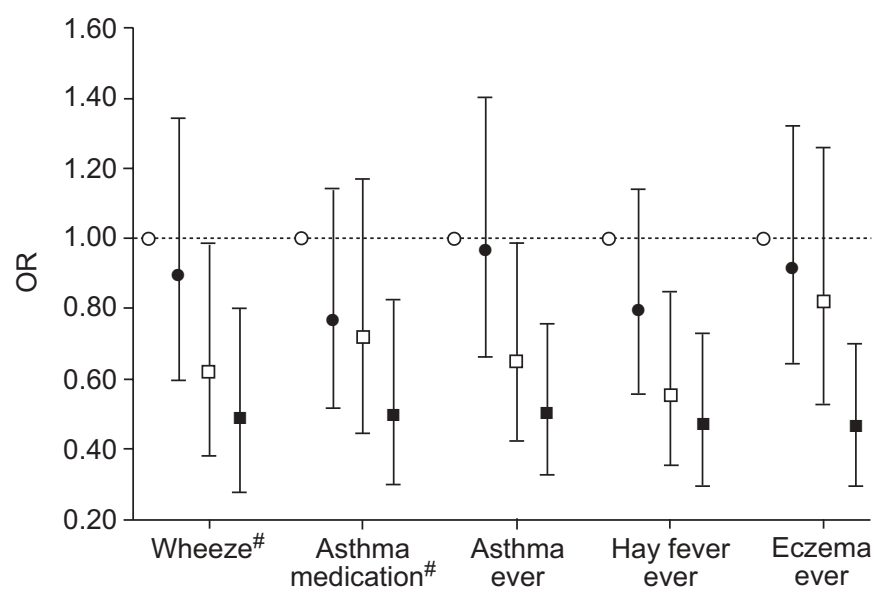

FIGURE 2. Adjusted odds ratios (OR) with $95 \%$ confidence intervals for the independent and joint effects of current and prenatal animal exposure. The analyses were adjusted for age, sex, ethnicity, smoking in the house, mother's education level, farm type, raw milk consumption, and parental asthma, hay fever and eczema. * : in last 12 months. $\bigcirc$ : never exposed (reference group), $n=1124$ - : only currently exposed, $n=247$; $\square$ : only prenatal exposure, $n=168$; $\mathbf{\square}$ : current and prenatal exposure, $n=231$ strongly associated with other farm exposures, such as hay and grain. Both animals and hay/grain products are associated with high exposures to microorganisms, particularly bacterial endotoxin [27], and prenatal farming exposure has also been shown to be associated with an upregulation of several innate immune receptors specific for microbial products (TLRs and CD14) [10]. Exposure to microorganisms and microbial products may, therefore, be an important intermediate factor and has been suggested to upregulate Th1 (through innate immune activation) and downregulate Th2 lymphocyte immunity, thereby suppressing the development of $\operatorname{IgE}$ antibodies and Th2-dependent diseases, including allergic asthma, hay fever and eczema [28]. However, the evidence for this is limited, and a study in farmers' children did not support the hypothesis that microbial exposures in farmers' children skew the Th1/Th2 balance toward Th1 responses [11]. Alternatively, microbial exposure may enhance the activity of regulatory Tcells, resulting in a downregulation of both Th2 and Th1 immunity [28]. However, the potential role of regulatory T-cells has, so far, not been studied in the context of farm exposures. Other studies in nonfarming populations have also shown inverse associations between bacterial endotoxin exposure in infancy and wheeze and asthma at a later age, emphasising the potential role of endotoxin exposure in these protective effects [29]. However, despite microbial exposure being a plausible reason for the reduced risk, farm exposures in New Zealand are likely to be different from those in Europe. In particular, in New Zealand, livestock is kept out in the field all year round, whereas in Europe they are kept in stables for at least part of the year. New Zealand farm children with frequent contact to animals are, therefore, likely to be less highly exposed than their counterparts in Europe. Hence, other factors associated with contact to farm animals may also be relevant. 
As previously shown $[2,10,30]$, the present study found that consumption of raw milk fresh from the farm was inversely associated with all studied outcomes. However, when other farm exposures were adjusted for, the protective effects largely disappeared. Thus, consumption of raw farm milk does not appear to be a significant protective factor in the current study.

In conclusion, prenatal farm exposures may protect against symptoms of asthma, hay fever and eczema in farmers' children. The results of the present study also suggest that continued exposure later in life may be required to maintain optimal protection, but confirmation from prospective studies is required to confirm this.

\section{ACKNOWLEDGEMENTS}

The authors are indebted to all farming and reference families for their participation. The authors also thank M. Gray, E. Harding, H. Duckett, J. Gedye, E. Gedye and A. Shum-Pearce (all at the Centre for Public Health Research, Massey University, Wellington, New Zealand) for their assistance in the data collection and data entry.

\section{REFERENCES}

1 Remes ST, Koskela HO, Iivanainen K, Pekkanen J. Allergen-specific sensitization in asthma and allergic diseases in children: the study on farmers' and nonfarmers' children. Clin Exp Allergy 2005; 35: 160-166.

2 Riedler J, Braun-Fahrländer C, Eder W, et al. Exposure to farming in early life and development of asthma and allergy: a cross-sectional survey. Lancet 2001; 358: 1129-1133.

3 Koskela HO, Happonen KK, Remes ST, Pekkanen J. Effect of farming environment on sensitisation to allergens continues after childhood. Occup Environ Med 2005; 62: 607-611.

4 Eduard W, Douwes J, Omenaas E, Heederik D. Do farming exposures cause or prevent asthma? Results from a study of adult Norwegian farmers. Thorax 2004; 59: 381-386.

5 Schulze A, van Strien RT, Praml G, Nowak D, Radon K. Characterisation of asthma among adults with and without childhood farm contact. Eur Respir J 2007; 29: 1169-1173.

6 Radon K, Schulze A, Nowak D. Inverse association between farm animal contact and respiratory allergies in adulthood: protection, underreporting or selection? Allergy 2006; 61: 443-446.

7 Smit LA, Zuurbier M, Doekes G, Wouters IM, Heederik D, Douwes J. Hay fever and asthma symptoms in conventional and organic farmers in The Netherlands. Occup Environ Med 2007; 64: 101-107.

8 Douwes J, Travier N, Huang K, et al. Lifelong farm exposure may strongly reduce the risk of asthma in adults. Allergy 2007; 62: 1158-1165.

9 Von Ehrenstein OS, Von Mutius E, Illi S, Baumann L, Böhm O, von Kries R. Reduced risk of hay fever and asthma among children of farmers. Clin Exp Allergy 2000; 30: 187-193.

10 Ege MJ, Bieli C, Frei R, et al. Prenatal farm exposure is related to the expression of receptors of the innate immunity and to atopic sensitization in school-age children. J Allergy Clin Immunol 2006; 117: 817-823.
11 Braun-Fahrländer C, Riedler J, Herz U, et al. Environmental exposure to endotoxin and its relation to asthma in school-age children. N Engl J Med 2002; 347: 869-877.

12 Yabuhara A, Macaubas C, Prescott SL, et al. TH2-polarized immunological memory to inhalant allergens in atopics is established during infancy and early childhood. Clin Exp Allergy 1997; 27: 1261-1269.

13 Romieu I, Torrent M, Garcia-Esteban R, et al. Maternal fish intake during pregnancy and atopy and asthma in infancy. Clin Exp Allergy 2007; 37: 518-525.

14 Devereux G, Litonjua AA, Turner SW, et al. Maternal vitamin D intake during pregnancy and early childhood wheezing. Am J Clin Nutr 2007; 85: 853-859.

15 Willers SM, Devereux G, Craig LC, et al. Maternal food consumption during pregnancy and asthma, respiratory and atopic symptoms in 5-year-old children. Thorax 2007; 62: 773-779.

16 Moshammer $\mathrm{H}$, Hoek G, Luttmann-Gibson $\mathrm{H}$, et al. Parental smoking and lung function in children: an international study. Am J Respir Crit Care Med 2006; 173: 1255-1263.

17 Sunyer J, Torrent M, Muñoz-Ortiz L, et al. Prenatal dichlorodiphenyldichloroethylene (DDE) and asthma in children. Environ Health Perspect 2005; 113: 1787-1790.

18 Willwerth BM, Schaub B, Tantisira KG, et al. Prenatal, perinatal, and heritable influences on cord blood immune responses. Ann Allergy Asthma Immunol 2006; 96: 445-453.

19 Alfvén T, Braun-Fahrländer C, Brunekreef B, et al. Allergic diseases and atopic sensitization in children related to farming and anthroposophic lifestyle - the PARSIFAL study. Allergy 2006; 61: 414-421.

20 Morgan WJ, Stern DA, Sherrill DL, et al. Outcome of asthma and wheezing in the first 6 years of life: follow-up through adolescence. Am J Respir Crit Care Med 2005; 172: 1253-1258.

21 Weiland SK, Björkstén B, Brunekreef B, Cookson WO, von Mutius E, Strachan DP. Phase II of the International Study of Asthma and Allergies in Childhood (ISAAC II): rationale and methods. Eur Respir J 2004; 24: 406-412.

22 Williams RL. A note on robust variance estimation for cluster-correlated data. Biometrics 2000; 56: 645-646.

23 Douwes J, Le Gros G, Gibson P, Pearce N. Can bacterial endotoxin exposure reverse atopy and atopic disease? J Allergy Clin Immunol 2004; 114: 1051-1054.

24 Kemp A, Björkstén B. Immune deviation and the hygiene hypothesis: a review of the epidemiological evidence. Pediatr Allergy Immunol 2003; 14: 74-80.

25 Holt P, Naspitz C, Warner JO. Early immunological influences. Chem Immunol Allergy 2004; 84: 102-127.

26 Holloway JA, Warner JO, Vance GH, Diaper ND, Warner JA, Jones CA. Detection of house-dust-mite allergen in amniotic fluid and umbilical-cord blood. Lancet 2000; 356: 1900-1902.

27 Douwes J, Pearce N, Heederik D. Does environmental endotoxin exposure prevent asthma? Thorax 2002; 57: 86-90.

28 Romagnani S. The increased prevalence of allergy and the hygiene hypothesis: missing immune deviation, reduced immune suppression, or both? Immunology 2004; 112: 352-363.

29 Douwes J, van Strien R, Doekes G, et al. Does early indoor microbial exposure reduce the risk of asthma? The 
Prevention and Incidence of Asthma and Mite Allergy birth cohort study. J Allergy Clin Immunol 2006; 117: 1067-1073.
30 Perkin MR, Strachan DP. Which aspects of the farming lifestyle explain the inverse association with childhood allergy? J Allergy Clin Immunol 2006; 117: 1374-1381. 